\title{
FIELD- AND STRESS-INDUCED MAGNETIC ANISOTROPY IN NANOCRYSTALLINE Fe-BASED AND AMORPHOUS Co-BASED ALLOYS
}

\author{
V.A. LUKSHINA*, N.V. DMITRIEVA and A.P. POTAPOV \\ Institute of Metal Physics, Russian Academy of Sciences, \\ S. Kovalevskaya st. 18, Ekaterinburg, 620219 Russia
}

(Received in final form 28 September 1997)

\begin{abstract}
For nanocrystalline alloy $\mathrm{Fe}_{73.5} \mathrm{Cu}_{1} \mathrm{Nb}_{3} \mathrm{Si}_{13.5} \mathrm{~B}_{9}$ thermomechanical treatment was carried out simultaneously with nanocrystallizing annealing (1) or after it (2). It was shown that a change in magnetic properties for the case 1 is essentially greater than for the case 2 . Complex effect of thermomagnetic and thermomechanical treatments on magnetic properties was studied in the above-mentioned nanocrystalline alloy as well as in the amorphous alloy $\mathrm{Fe}_{5} \mathrm{Co}_{70.6} \mathrm{Si}_{15} \mathrm{~B}_{9.4}$. During the annealings both field and stress were aligned with the long side of the specimens. It was shown that the magnetic field, AC or DC, decreases an effect of loading. Moreover, the magnetic field, AC or DC, applied after stress-annealing can destroy the magnetic anisotropy already induced under load.
\end{abstract}

Keywords: Nanocrystalline and amorphous alloys; Induced magnetic anisotropy

\section{INTRODUCTION}

Nanocrystalline Fe-based alloys are known as a unique magnetically soft material with a low coercive force, low magnetic losses, and high magnetic permeability, which is caused by very fine grain size $(10-12 \mathrm{~nm})$, random distribution of crystal axes of grains, and vanishing total magnetostriction. It was known that (Glazer et al., 1991) using thermomechanical treatment, magnetic anisotropy of the easy-plane type characteristic of Co-based alloys (Nielsen et al., 1985) may be

\footnotetext{
* Corresponding author.
} 
obtained in the $\mathrm{Fe}_{73.5} \mathrm{Cu}_{1} \mathrm{Nb}_{3} \mathrm{Si}_{13.5} \mathrm{~B}_{9}$ alloy. This work is a continuation of Glazer et al. (1991). Its aim is to study for Fe-based nanocrystalline alloy the effect of the conditions of thermomechanical and thermomagnetic treatments on the magnitude of induced magnetic anisotropy and to compare the data with those for Co-based amorphous alloy $\mathrm{Fe}_{5} \mathrm{Co}_{70.6} \mathrm{Si}_{15} \mathrm{~B}_{9.4}$.

\section{EXPERIMENTAL}

The method of rapidly quenching the melt onto a rotating copper drum was used to prepare amorphous ribbons of both $\mathrm{Fe}$ - and Co-based alloys of $20 \mu \mathrm{m}$ in thickness and $1 \mathrm{~mm}$ in width. In order to obtain a nanocrystalline state, the Fe-based ribbons were annealed in air at $530^{\circ} \mathrm{C}$ for $1 \mathrm{~h}$. Below, we will call this treatment nanocrystallizing annealing (NCA). For both alloys the thermomechanical (TMechT), or thermomagnetic (TMT), or thermomechanomagnetic (TMechMT) treatment, that involve annealing and cooling of the sample under a tensile load, or in a magnetic field, or upon both factors, was carried out in a vertical tubular furnace; a load was fastened to the ribbon using a special clamp and removed after the termination of the treatment. The longitudinal magnetic field $H=400 \mathrm{Oe}, \mathrm{DC}$ or AC, was created by coil winded around the furnace. For $\mathrm{Fe}$-based material the treatment was performed using two regimes:

1. The NCA was carried out simultaneously with TMechT, or TMT, or TMechMT. An amorphous sample was subjected to NCA with a tensile load, or a magnetic field, or both a load and a magnetic field simultaneously.

2. NCA and TMechT, or TMT, or TMechMT were performed sequentially; the sample that was preliminarily annealed to obtain the nanocrystalline condition was then subjected to one of three treatments.

From a ribbon subjected to such a treatment, samples of $80-100 \mathrm{~mm}$ in length were cut from a portion that was located in the zone of the controlled uniform heating. Magnetic properties (hysteresis loops) were measured by the ballistic method in a field directed along the ribbon.

Similar to thermomagnetic treatment in transverse DC magnetic field the thermomechanical one increases the incline of the hysteresis loops; 


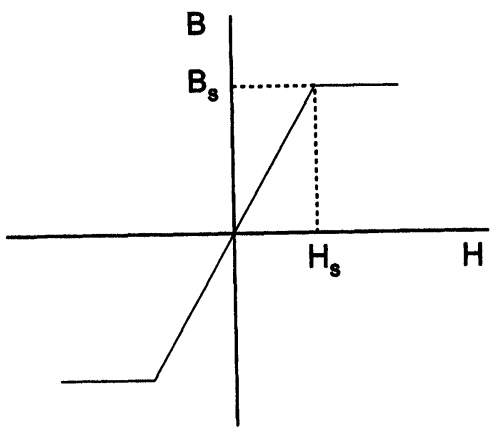

FIGURE 1 Appearance of the hysteresis loop for $\mathrm{Fe}_{73.5} \mathrm{Cu}_{1} \mathrm{Nb}_{3} \mathrm{Si}_{13.5}$ B-specimens after stress- or field-treatment in transverse DC magnetic field.

with increasing load, the slope of the loop increases (Glazer et al., 1991). The constant of induced magnetic anisotropy $K_{\mathrm{u}}$ was determined from a relation $K_{\mathrm{u}}=-0.5 M_{\mathrm{s}} H_{\mathrm{s}}$ (see Fig. 1), where $M_{\mathrm{s}}$ is the saturation magnetization and $H_{\mathrm{s}}$ is the saturating field (in which saturation magnetization is reached). The error of measuring $K_{\mathfrak{u}}$ was $5-7 \%$.

\section{RESULTS AND DISCUSSION}

The results of the investigations are shown in the figures and in the tables.

For nanocrystalline alloy Fig. 2 shows the variation of the constant of induced magnetic anisotropy depending on the load during TMechT at $530^{\circ} \mathrm{C}$ for $1 \mathrm{~h}$ according to regimes 1 and 2 (curves 1 and 2, respectively). It can be seen that, first, the magnitude of $K_{\mathrm{u}}$ induced by TMechT increases with increasing load, the magnitude of $K_{\mathrm{u}}$ after TMechT by regime 1 is substantially larger than that obtained after treatment by regime 2 . The times for reaching maximum $K_{\mathrm{u}}$ upon treatment by regimes 1 and 2 are also substantially different. When TMechT is performed at $530^{\circ} \mathrm{C} K_{\mathrm{u}}$ reaches its maximum in a few minutes if TMechT is combined with NCA, but only in more than $1 \mathrm{~h}$ if TMechT follows NCA. It was noted also that ribbons treated by regime 1 increase in length. The larger the load, the greater the elongation; at maximum loads it reaches $13-15 \mathrm{~mm}$, which is equal to about $15 \%$ of the gage length of the ribbon. The elongation occurs in approximately the same 


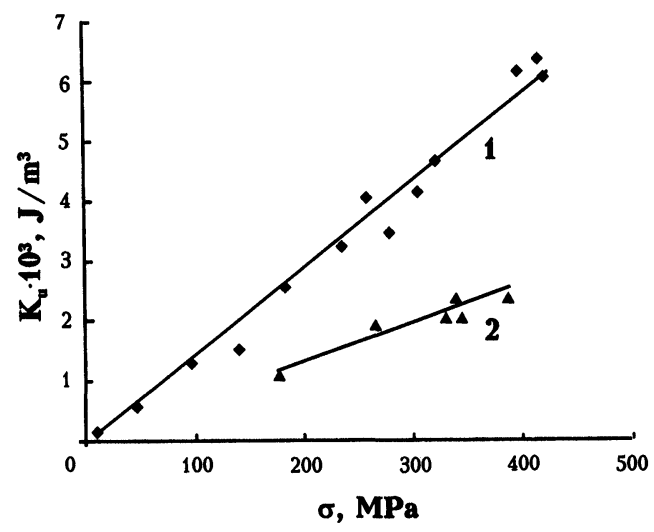

FIGURE 2 Variation of the constant of induced magnetic anisotropy $K_{\mathrm{u}}$ depending on the load during TMechT; (1) regime 1 : TMechT is combined with NCA $\left(530^{\circ} \mathrm{C}\right.$, $1 \mathrm{~h})$; (2) regime 2: TMechT $\left(530^{\circ} \mathrm{C}, 1 \mathrm{~h}\right)$ follows NCA $\left(530^{\circ} \mathrm{C}, 1 \mathrm{~h}\right)$.

TABLE I $K_{\mathrm{u}}$ values for nanocrystalline specimens subjected to TMechT or TMechMT

\begin{tabular}{lcccccc}
\hline Load at TMechT or TMT, MPa & 7 & 30 & 50 & 100 & 150 & 215 \\
$K_{\mathrm{u}}$ after TMechT, $\mathrm{J} / \mathrm{m}^{3}$ & 110 & 285 & 500 & 1120 & 1620 & 2300 \\
$K_{\mathrm{u}}$ after TMechT in DC H, J/m $\mathrm{m}^{3}$ & 95 & 260 & 465 & 1030 & 1580 & 2230 \\
$K_{\mathrm{u}}$ decrease, \% & -14 & -9 & -7 & -3 & -3 & -3 \\
$K_{\mathrm{u}}$ after TMechT in AC H, J/m & 85 & 250 & 445 & 1080 & 1630 & 2260 \\
$K_{\mathrm{u}}$ decrease, $\%$ & -23 & -12 & -11 & -4 & +0.5 & -2 \\
\hline
\end{tabular}

time, in which $K_{\mathrm{u}}$ reaches its maximum value, i.e. in a few minutes. No elongation was observed when treating ribbons by regime 2 .

The Table I shows the $K_{\mathrm{u}}$ behavior for Fe-based specimens subjected to NCA simultaneously with TMechT in a magnetic field, AC or DC, at $530^{\circ} \mathrm{C}$ for $1 \mathrm{~h}$. In addition, the percent of the $K_{\mathrm{u}}$ value decrease after TMechMT is shown in comparison with that after TMechT. One can see that the magnetic field decreases an effect of loading to $50 \mathrm{MPa}$; the less the load, the more the decrease. At loads more than $50 \mathrm{MPa}$ the change of $K_{\mathrm{u}}$ is less than $5 \%$ which is within the error of measuring $K_{\mathrm{u}}$.

Figure 3 shows the hysteresis loops of Fe-based specimens subjected to NCA at $530^{\circ} \mathrm{C}$ for $1 \mathrm{~h}$ under load $\sigma=30 \mathrm{MPa}$. Cooling of specimens after this treatment proceeded in different ways: under load $\sigma=30 \mathrm{MPa}$ (a); without anyload (b); without anyload in longitudinalDC(c) or AC(d) magnetic field $H=400 \mathrm{Oe}$. Co-based amorphous specimens were subjected to analogous treatment, what means annealing at $300^{\circ} \mathrm{C}$ for $1 \mathrm{~h}$ 


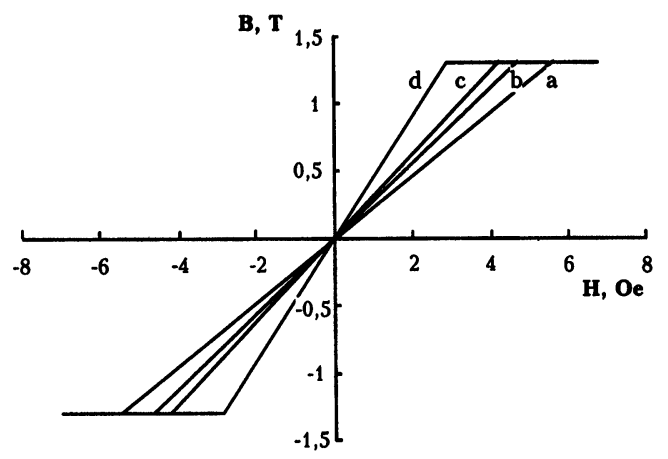

FIGURE 3 Hysteresis loops after $1 \mathrm{~h}$ annealing under load $\sigma=30 \mathrm{MPa}$ at temperature $T=530^{\circ} \mathrm{C}$ followed by cooling under the load (a), without any load (b), without any load in magnetic DC (c) and AC (d) field $H=400 \mathrm{Oe}$.

TABLE II $K_{\mathrm{u}}$ magnitudes for nanocrystalline and amorphous specimens subjected to stress-annealing followed by cooling in different conditions

\begin{tabular}{lccccc}
\hline $\begin{array}{l}\text { Cooling mode after } \\
\text { stress-annealing for alloys }\end{array}$ & \multicolumn{2}{c}{$K_{\mathrm{u}}, \mathrm{J} / \mathrm{m}^{3}$} & & \multicolumn{2}{c}{$K_{\mathrm{u}}$ decrease, \% } \\
\cline { 2 - 3 } & Fe-based & Co-based & & Fe-based & Co-based \\
\hline Under load & 285 & 280 & & -16 & -14 \\
Without any load & 240 & 240 & & -23 & -39 \\
Without any load in DC field & 220 & 170 & & -47 & -54 \\
Without any load in AC field & 150 & 130 & & -47 \\
\hline
\end{tabular}

under load $\sigma=600 \mathrm{MPa}$ and cooling: under load $\sigma=600 \mathrm{MPa}$ (a), without any load (b); without any load in longitudinal DC (c) or AC (d) magnetic field $H=400$ Oe.

The Table II shows the values of $K_{\mathrm{u}}$ after different coolings for both alloys. Also, it shows a percent of $K_{\mathrm{u}}$ decrease after cooling without any load and in magnetic fields in comparison with $K_{\mathrm{u}}$ after cooling under load. It is seen that after cooling without any load $K_{\mathrm{u}}$ decreases by $16 \%$ for Fe-based and $14 \%$ for Co-based alloys, and after cooling in a magnetic field much larger, particularly in AC one. It means that cooling in magnetic field can destroy magnetic anisotropy induced under load.

\section{CONCLUSION}

1. The magnitude of the constant of induced magnetic anisotropy that can be obtained by TMechT increases with increasing tensile stresses. 
2. The combined effect of NCA and TMechT, all other conditions being the same, produces a greater induced anisotropy than that obtained when TMechT follows NCA.

3. Magnetic field can interfere with the induction of magnetic anisotropy during stress-annealing and destroy the already stress-induced one.

\section{Acknowledgements}

The work was supported by the Russian Fund for Basic Research, Pr. No. 96-02-16000.

\section{References}

Glazer, A.A., Kleinerman, N.M., Lukshina, V.A., Potapov, A.P. and Serikov, V.V.(1991). Thermomechanical treatment of a nanocrystalline alloy $\mathrm{Fe}_{73.5} \mathrm{Cu}_{1} \mathrm{Nb}_{3} \mathrm{Si}_{13.5} \mathrm{~B}_{9}$. The Physics of Metals and Metallography, 72(6), 56-61.

Herzer, G. (1994). Creep induced magnetic anisotropy in nanocrystalline $\mathrm{Fe}-\mathrm{Cu}-\mathrm{Nb}-$ $\mathrm{Si}-\mathrm{B}$ alloys. IEEE Transaction on Magnetics, 30(6), 4800-4802.

Nielsen, O.V., Hernando, A., Madurga, V. and Gonzales, J.M. (1985). Experiments concerning the origin of stress anneal induced magnetic anisotropy in metallic glass ribbons. Journal of Magnetism and Magnetic Materials, 46(3), 341-349. 